\title{
Factors Related to Nocturia in Elderly People Living in Local Remote Area in Japan
}

\author{
Yuko Takeda1 $^{*}$, Mitsumi Ono¹, Hideyuki Kanda², Sachiko Hara' ${ }^{1}$, Keiko Takeda ${ }^{3}$ \\ ${ }^{1}$ Department of Community Health and Gerontological Nursing, Faculty of Medicine, Shimane University, Izumo, Japan \\ ${ }^{2}$ Department of Environmental Medicine and Public Health, Faculty of Medicine, Shimane University, Izumo, Japan \\ ${ }^{3}$ Department of Nursing, Faculty of Health and Welfare, Kawasaki University of Medical Welfare, Okayama, Japan \\ Email: *y.takeda@med.shimane-u.ac.jp
}

How to cite this paper: Takeda, Y., Ono, M., Kanda, H., Hara, S. and Takeda, K. (2017) Factors Related to Nocturia in Elderly People Living in Local Remote Area in Japan. Health, 9, 657-668.

https://doi.org/10.4236/health.2017.94047

Received: February 21, 2017

Accepted: April 18, 2017

Published: April 21, 2017

Copyright $\odot 2017$ by authors and Scientific Research Publishing Inc. This work is licensed under the Creative Commons Attribution International License (CC BY 4.0).

http://creativecommons.org/licenses/by/4.0/

\begin{abstract}
The elderly people are prone to be affected by quality of life (QOL) by nocturia becoming the multiple times. A purpose of this study was to determine it about a factor associated with the night urination. This survey was conducted in 2015 as a cross-sectional study. Anonymous, self- administered questionnaires were used to prevent individuals from being identified. The analysis subjects were 699 elderly people with the nocturia which belonged to club of the aged 65 years or older. Those with nocturia were placed in the Nocturia-1 group if they reported experiencing nocturia once per night or in the Nocturia- $\geq 2$ group if they reported experiencing nocturia two or more times per night. We analyzed the relationships between the characteristics, lower urinary tract symptoms, and opportunities to go outdoors in the Nocturia-1 and Nocturia- $\geq 2$ groups based on sex using the $x^{2}$ test. In addition, to investigate the factors that influence the change from nocturia once per night to two or more times per night, we performed logistic regression analysis using the $x^{2}$ test on the characteristics and lower urinary tract symptoms that showed significant differences separately for men and women. Among the men, factors with a significant positive relationship were age, diabetes mellitus, lower back pain, daytime frequency, and urinary urgency. Among the women, factors with a significant positive relationship were age, requiring support 1-requiring long-term care 2, urinary urgency, and feeling of incomplete emptying. It was suggested that the life of elderly people improved by nocturia not increasing.
\end{abstract}

\section{Keywords}

Elderly, Nocturia, Quality of Life

\section{Introduction}

Lower urinary tract symptom is associated with impaired quality of life (QOL). 
According to a survey [1] of local community dwellers ranging from adults to the elderly that was conducted, of all the lower urinary tract symptoms, the most troublesome were abdominal pressure-induced incontinence, urinary urgency, and nocturia. In contrast, according to a large-scale nationwide survey of local community dwellers aged $\geq 40$ years that was conducted in Japan, the number of people who experience nocturia at least once per night increased with age. In addition, the survey found that nocturia had the greatest influence on the daily lives of men belonging to all age groups and that for women, it had the greatest influence on the daily lives along with abdominal pressure-induced incontinence [2]. Therefore, nocturia is considered to be one of the most troublesome lower urinary tract symptoms that has a major effect on the daily lives of not only elderly men but also women. Approximately half of those who awaken three or more times per night for going to the toilet feel that their sleep is obstructed by this urge [3]. Another survey [4] indicated that older people report more nocturnal and early morning awakening than young people. It is considered that repeatedly getting up during the night to urinate may lead to chronic sleep problems and lessen the motivation to engage in activities the following day or participate in activities in general. Therefore, it is possible that waking up multiple times during the night to use the toilet affects not only the physical condition of the elderly but also their daily activities and QOL. Compared with those who live in urban areas, the elderly who live in low-lying mountainous areas may more often observe that nocturia affects behaviors such as lessening the motivation to leave the area where they reside for visiting the hospital or to engage in agriculture. A survey of adults [5] found that approximately $60 \%$ of those who experience nocturia two or more times during the night also experience a decreased QOL, which often represents a clinical problem. It has also been reported [6] that the elderly who experience symptoms of nocturia two or more times have a higher risk of falling during the night than those who experience nocturia symptoms once or less often. Therefore, when investigating the effects of nocturia on QOL, it is considered necessary to particularly focus on those who experience nocturia two or more times per night.

A review [7] of factors related to nocturia reported that age, sex, history of illnesses such as hypertension and diabetes, lower urinary tract symptoms other than nocturia, sleeping conditions, and drug use were related to the condition. However, the factors specifically related to nocturia in the elderly have not yet been fully elucidated. It is possible to predict that if the elderly experience a decline in their physical functions, problems in their daily lives will worsen and that based on their previous relationships, they will have to depend upon the assistance of either family members and close neighbors or public health and welfare services. Compared with urban areas, in low-lying mountainous areas, where there is a high percentage of elderly people, there are insufficient means to visit specialists such as urologists. As people age, they are more likely to restrict their range of activities as a result of illnesses or disabilities. In other words, there is a need to support the elderly to live in communities that they are most 
familiar with so that they can continue to lead the kinds of lives they desire.

The purpose of this study was to elucidate factors related to nocturia two or more times per night in the elderly for helping the elderly living in local remote area in Japan in maintaining their QOL.

\section{Subjects and Methods}

This survey was conducted in 2015 as a cross-sectional study. The subjects comprised all 1,245 elderly people aged $\geq 65$ years who were members of a senior citizen's club and resided in town A located in a low-lying mountainous area. The president of the senior citizen's club was asked to distribute forms requesting participation in the survey and questionnaires. We received 945 responses (response rate: $75.9 \%)$. After excluding those who submitted invalid responses ( $\mathrm{n}=$ 147), reported no nocturia $(\mathrm{n}=86)$, and required a long-term care level of 3 - 5 $(\mathrm{n}=11)$, a total of 699 respondents $(56.1 \%)$ were subjected to analysis. A survey [8] of general conditions at nursing care service and office facilities indicated that the average level of long-term care need at long-term care facilities for the elderly was 3.87 and that approximately $90 \%$ of the residents required a long-term care level of at least 3. It also indicated that the average level of required long-term care at geriatric healthcare facilities was 3.26 and that $70 \%$ of the residents required a long-term care level of at least 3 . Therefore, because the subjects of this study were elderly people living at home in low-lying mountainous areas wherein they were accustomed to living, we excluded those who required a long-term care level of 3 - 5, which corresponds to elderly people residing in facilities who require more attention, from the analysis.

Anonymous, self-administered questionnaires were used to prevent individuals from being identified. Each questionnaire was sealed in an envelope and either mailed or hand delivered to the person in charge of the senior citizen's club. Questionnaires were distributed between the end of March and the beginning of April 2015, and the deadline for returning the completed questionnaire form was the end of May 2015. The contents of the questionnaire were as follows: basic subject attributes (sex, age, family composition, level of long-term care need, and history of current illness), number of times nocturia is experienced, lower urinary tract symptoms (daytime frequency, urinary urgency, urgency incontinence, feeling of incomplete emptying, bladder pain, and urethral pain), and opportunities to go outdoors. The question regarding nocturia was "While you slept, how many times did you do urine?" The responses were " 1 time," "2 times," " 3 times," and " 4 times or more." The questions regarding lower urinary tract symptoms asked respondents to consider urination over the past week. The question regarding daytime frequency was "Roughly how many times did you urinate from the time you woke up in the morning until the time you went to sleep?" The responses were "7 times or fewer," "8 to 9 times," "10 to 14 times," and "15 times or more." The question regarding urinary urgency was "How frequently did you feel like urinating to the extent that you were unable to wait?" The question regarding urgency incontinence was "How frequently were you 
unable to prevent leakage?" The question regarding feeling of incomplete emptying was "How frequently do you feel that you have residual urine after you urinate?" The question regarding lower bladder pain was "How frequently did you feel pain in the bladder (lower abdomen)?" The question regarding urethral pain was "How frequently did you feel urethral pain?" Responses to the other questions related to lower urinary tract symptoms other than daytime frequency were selected from the following four choices: "Never," "Rarely," "Sometimes," and "Always." Homma et al have been reported that weighted kappa coefficient was 0.82 for the total score of the core lower urinary tract symptom score among 29 patients who presented with lower urinary tract symptom [9]..All the procedures of this study were reviewed and approved by the Institution Review Board of Kawasaki University of Medical Welfare (Approval No.: 14-045). We conducted this investigation according to the Ethic guideline about the medical system study for people.

Statistical analysis was separately conducted for men and women based on the fact that there are anatomical structural differences between the sexes as well as differences in the frequency of going outdoors and social and recreational activities [10]. Those with nocturia were placed in the Nocturia-1 group if they reported experiencing nocturia once per night or in the Nocturia- $\geq 2$ group if they reported experiencing nocturia two or more times per night. Age groups were divided according to 5 -years brackets. Family composition was divided into "Lives with family" and "Lives alone." The level of long-term care need was set at either "No certification" or "Requiring support 1 to requiring long-term care 2." History of current illnesses (hypertension, diabetes mellitus, heart disease, cancer, lower back pain, knee osteoarthritis, Parkinson's disease, benign prostatic hyperplasia, depression) was classified as either "Yes" or "No." Daytime frequency was handled as follows: those who responded " 7 times or fewer" were placed in the "No" group, and those who responded "8 to 9 times," "10 to 14 times," or "15 times or more" were placed in the "Yes" group. Those who responded "Never" to the items related to lower urinary tract symptoms other than daytime frequency were placed in the "No" group and those who responded "Rarely," "Sometimes," or "Always" were placed in the "Yes" group. Opportunities to go outdoors were classified as either "Yes" or "No."

We analyzed the relationships between age, family composition, level of long-term care need, history of current illness, lower urinary tract symptoms, and opportunities to go outdoors in the Nocturia-1 and Nocturia- $\geq 2$ groups based on sex using the $x^{2}$ test. In addition, to investigate the factors that influence the change from nocturia once per night to two or more times per night, we performed logistic regression analysis using the $\chi^{2}$ test on the characteristics and lower urinary tract symptoms that showed significant differences separately for men and women. The level of significance on both sides was $5 \%$. Data was collected and statistical analysis was performed using IBM SPSS ${ }^{\circ}$ Statistics (IBM JAPAN Co., version 21.0, Tokyo, Japan). 


\section{Results}

Of the valid responses received from 699 subjects ( 314 men and 385 women), 300 (113 men, 187 women) were assigned to the Nocturia-1 group and 399 (201 men, 198 women) to the Nocturia- $\geq 2$ group.

Table 1 shows characteristics of elderly people in the Nocturia-1 and Nocturia- $\geq 2$ groups. Among the men, those in the Nocturia- $\geq 2$ group were significantly older than those in the Nocturia-1 group and many had diabetes mellitus and lower back pain. Among the women, those in the Nocturia- $\geq 2$ group were significantly older than those in the Nocturia-1 group, many lived alone, and many requiring support 1 to long-term care 2 .

Table 1. Characteristics of elderly people in the Nocturia-1 and Nocturia- $\geq 2$ groups.

\begin{tabular}{|c|c|c|c|c|c|c|}
\hline & \multicolumn{3}{|c|}{ Men } & \multicolumn{3}{|c|}{ Women } \\
\hline & Nocturia-1 & Nocturia- $\geq 2$ & $p$-value & Nocturia-1 & Nocturia- $\geq 2$ & $p$-value \\
\hline & $\mathrm{n}=113$ & $\mathrm{~N}=201$ & & $\mathrm{~N}=187$ & $\mathrm{~N}=198$ & \\
\hline & n (\%) & $\mathrm{n}(\%)$ & & $\mathrm{n}(\%)$ & n (\%) & \\
\hline \multicolumn{7}{|l|}{ Age (+5 years) } \\
\hline $65-69$ & $31(27.4)$ & $26(12.9)$ & $<0.01$ & $41(21.9)$ & $14(7.1)$ & $<0.01$ \\
\hline $70-74$ & $26(23.0)$ & $27(13.4)$ & & $33(17.6)$ & $31(15.7)$ & \\
\hline $75-79$ & $26(23.0)$ & $53(26.4)$ & & $45(24.1)$ & $45(22.7)$ & \\
\hline $80-84$ & $21(18.6)$ & $55(27.4)$ & & $45(24.1)$ & $61(30.8)$ & \\
\hline $85-89$ & $8(7.1)$ & $29(14.4)$ & & $17(9.1)$ & $29(14.6)$ & \\
\hline $90-$ & $1(0.9)$ & $11(5.5)$ & & $6(3.2)$ & $18(9.1)$ & \\
\hline \multicolumn{7}{|l|}{ Family composition } \\
\hline lives with family & $106(93.8)$ & $178(88.6)$ & 0.13 & $161(86.1)$ & $152(76.8)$ & 0.02 \\
\hline lives alon & $7(6.2)$ & $23(11.4)$ & & $26(13.9)$ & $46(23.2)$ & \\
\hline \multicolumn{7}{|l|}{$\begin{array}{l}\text { Level of long-term } \\
\text { care need }\end{array}$} \\
\hline no certification & $109(96.5)$ & $184(91.5)$ & 0.09 & $182(97.3)$ & $171(86.4)$ & $<0.01$ \\
\hline requiring support 1 & $4(3.5)$ & $17(8.5)$ & & $5(2.7)$ & $27(13.6)$ & \\
\hline \multicolumn{7}{|c|}{-requiring long-term care 2} \\
\hline \multicolumn{7}{|c|}{ History of current illness } \\
\hline hypertension & $58(51.3)$ & $122(60.7)$ & 0.11 & $95(50.8)$ & $112(56.6)$ & 0.26 \\
\hline diabetes mellitus & $10(8.8)$ & $41(20.4)$ & 0.01 & $21(11.2)$ & $22(11.1)$ & 0.97 \\
\hline heart disease & $11(9.7)$ & $25(12.4)$ & 0.47 & $17(9.1)$ & $24(12.1)$ & 0.34 \\
\hline cancer & $6(5.3)$ & $8(4.0)$ & 0.58 & $4(2.1)$ & $0(0.0)$ & 0.06 \\
\hline lower back pain & $5(4.4)$ & $44(21.9)$ & $<0.01$ & $34(18.2)$ & $49(24.7)$ & 0.12 \\
\hline knee osteoarthritis & $7(6.2)$ & $25(12.4)$ & 0.08 & $28(15.0)$ & $29(14.6)$ & 0.93 \\
\hline Parkinson's disease & $1(0.9)$ & $4(2.0)$ & 0.41 & $0(0.0)$ & $2(1.0)$ & 0.26 \\
\hline $\begin{array}{c}\text { benign prostatic } \\
\text { hyperplasia }\end{array}$ & $15(13.3)$ & $39(19.4)$ & 0.17 & - & - & - \\
\hline depressin & $1(0.9)$ & $2(1.0)$ & 0.71 & $4(2.1)$ & $2(1.0)$ & 0.32 \\
\hline
\end{tabular}

p-value for $\chi^{2}$ test. 
Table 2 shows lower urinary tract symptoms of elderly people in the Nocturia-1 and Nocturia- $\geq 2$ groups had lower urinary tract symptoms. Among the men, a significantly higher number of those in the Nocturia- $\geq 2$ group had all the lower urinary tract symptoms compared with those in the Nocturia-1 group. Among the women, a significantly higher number of those in the Nocturia- $\geq 2$ group had all the lower urinary tract symptoms, except for frequent daytime urination, than those in the Nocturia-1 group.

Table 3 shows opportunities to go outdoors for elderly people in the Nocturia-1 and Nocturia- $\geq 2$ groups. Among the men, a significantly higher number

Table 2. Lower urinary tract symptoms of elderly people in the Nocturia-1 and Nocturia$\geq 2$ groups.

\begin{tabular}{|c|c|c|c|c|c|c|c|}
\hline & & \multicolumn{2}{|c|}{ Men } & \multicolumn{4}{|c|}{ Women } \\
\hline & & Nocturia-1 & Nocturia- $\geq 2$ & $p$-value & Nocturia-1 & Nocturia- $\geq 2$ & $p$-value \\
\hline & & $\mathrm{n}=113$ & $\mathrm{n}=201$ & & $\mathrm{n}=187$ & $\mathrm{n}=198$ & \\
\hline & & $\mathrm{n}(\%)$ & $\mathrm{n}(\%)$ & & $\mathrm{n}(\%)$ & $\mathrm{n}(\%)$ & \\
\hline \multicolumn{8}{|c|}{ Lower urinary tract symptoms } \\
\hline daytime frequency & yes & $40(35.4)$ & $121(60.2)$ & $<0.01$ & $79(42.2)$ & $96(48.5)$ & 0.22 \\
\hline urinary urgency & yes & $61(54.0)$ & $165(82.1)$ & $<0.01$ & $96(51.3)$ & $157(79.3)$ & $<0.01$ \\
\hline urgency incontinence & yes & $28(24.8)$ & $86(42.8)$ & $<0.01$ & $65(34.8)$ & $120(60.6)$ & $<0.01$ \\
\hline $\begin{array}{l}\text { feeling of incomplete } \\
\text { emptying }\end{array}$ & yes & $43(38.1)$ & $104(51.7)$ & 0.02 & $34(18.2)$ & $81(40.9)$ & $<0.01$ \\
\hline bladder pain & yes & $3(2.7)$ & $22(10.9)$ & 0.01 & $8(4.3)$ & $22(11.1)$ & 0.01 \\
\hline urethral pain & yes & $5(4.4)$ & $23(11.4)$ & 0.04 & $4(2.1)$ & $13(6.6)$ & 0.03 \\
\hline
\end{tabular}

p-value for $x^{2}$ test yes: Nomber of the subjects who responded "Rarely," "Sometimes," and "Always".

Table 3. Opportunities to go outdoors for elderly people in the Nocturia-1 and Nocturia$\geq 2$ groups.

\begin{tabular}{ccccccc}
\hline & \multicolumn{5}{c}{ Men } & \multicolumn{3}{c}{ Women } \\
\hline & Nocturia-1 & Nocturia- $\geq 2$ & $p$-value & Nocturia-1 & Nocturia- $\geq 2$ & $p$-value \\
\hline & $\mathrm{n}=113$ & $\mathrm{~N}=201$ & & $\mathrm{~N}=187$ & $\mathrm{~N}=198$ & \\
& $\mathrm{n}(\%)$ & $\mathrm{n}(\%)$ & & $\mathrm{n}(\%)$ & $\mathrm{n}(\%)$ & \\
visit the hospital & $49(43.4)$ & $113(56.2)$ & 0.03 & $95(50.8)$ & $128(64.6)$ & 0.01 \\
visit the day care service facility & $4(3.5)$ & $13(6.5)$ & 0.27 & $8(4.3)$ & $21(10.6)$ & 0.02 \\
shopping & $67(59.3)$ & $137(68.2)$ & 0.11 & $148(79.1)$ & $130(65.7)$ & $<0.01$ \\
work & $82(72.6)$ & $109(54.2)$ & $<0.01$ & $85(45.5)$ & $65(32.8)$ & 0.01 \\
local meeting & $34(30.1)$ & $56(27.9)$ & 0.68 & $50(26.7)$ & $65(32.8)$ & 0.19 \\
hobbies & $30(26.5)$ & $57(28.4)$ & 0.73 & $55(29.4)$ & $31(15.7)$ & $<0.01$ \\
meeting friends & $21(18.6)$ & $42(20.9)$ & 0.62 & $72(38.5)$ & $46(23.2)$ & $<0.01$ \\
entertainment & $17(15.0)$ & $19(9.5)$ & 0.14 & $25(13.4)$ & $14(7.1)$ & 0.04 \\
care of the parent & $0(0.0)$ & $3(1.5)$ & 0.26 & $3(1.6)$ & $2(1.0)$ & 0.47 \\
care of the grandchild & $7(6.2)$ & $4(2.0)$ & 0.06 & $13(7.0)$ & $4(2.0)$ & 0.02 \\
walk & $30(26.5)$ & $56(27.9)$ & 0.80 & $63(33.7)$ & $64(32.3)$ & 0.78 \\
\hline
\end{tabular}

p-value for $\chi^{2}$ test. 
in the Nocturia- $\geq 2$ group went outdoors to visit the hospital, although many did not go outdoors for the purpose of work. Among the women, a significantly higher number in the Nocturia- $\geq 2$ group went outdoors to visit the hospital or day care service facility, although many did not go outdoors for the purpose of shopping, work, hobbies, meeting friends, entertainment, or taking care of the grandchild.

Table 4 shows factors based on sex that affected change in nocturia from once per night to two or more times per night. Among the men, factors with a significant positive relationship were age, diabetes mellitus, lower back pain, daytime frequency, and urinary urgency. Among the women, factors with a significant positive relationship were age, requiring support 1-requiring long-term care 2, urinary urgency, and feeling of incomplete emptying.

Table 4. The factors related to change to a nocturia frequency of two or more times per night, determined using multiple logistic regression analysis.

\begin{tabular}{|c|c|c|c|c|}
\hline & OR & \multicolumn{3}{|c|}{$95 \% \mathrm{CI}$} \\
\hline \multicolumn{5}{|l|}{ Characteristics } \\
\hline age ( +5 years $)$ & 1.41 & 1.15 & to & 1.72 \\
\hline diabetes mellitus $(0=$ no, $1=$ yes $)$ & 2.85 & 1.25 & to & 6.47 \\
\hline lower back pain $(0=$ no, $1=$ yes $)$ & 4.97 & 1.81 & to & 13.63 \\
\hline \multicolumn{5}{|l|}{ Lower urinary tract symptoms } \\
\hline daytime frequency $(0=$ no, $1=$ yes $)$ & 2.26 & 1.32 & to & 3.88 \\
\hline urinary urgency $(0=$ no, $1=$ yes $)$ & 2.90 & 1.53 & to & 5.46 \\
\hline urgency incontinence $(0=$ no, $1=$ yes $)$ & 1.06 & 0.57 & to & 1.97 \\
\hline feeling of incomplete emptying $(0=$ no, $1=$ yes $)$ & 0.98 & 0.55 & to & 1.73 \\
\hline bladder pain $(0=$ no, $1=$ yes $)$ & 2.70 & 0.70 & to & 10.40 \\
\hline \multirow[t]{2}{*}{ urethral pain $(0=$ no, $1=$ yes $)$} & 2.22 & 0.68 & to & 7.28 \\
\hline & OR & \multicolumn{3}{|c|}{$95 \% \mathrm{CI}$} \\
\hline \multicolumn{5}{|l|}{ Women } \\
\hline \multicolumn{5}{|l|}{ Characteristics } \\
\hline age $(+5$ years $)$ & 1.35 & 1.14 & to & 1.60 \\
\hline family composition ( 0 = lives with family, 1 = lives alon $)$ & 1.40 & 0.77 & to & 2.54 \\
\hline $\begin{array}{c}\text { level of long-term care need } \\
(0=\text { no certification, } 1 \text { = requiring support } 1-\text { requiring long-term care } 2)\end{array}$ & 3.12 & 1.08 & to & 9.07 \\
\hline \multicolumn{5}{|l|}{ Lower urinary tract symptoms } \\
\hline urinary urgency $(0=$ no, $1=$ yes $)$ & 2.58 & 1.46 & to & 4.57 \\
\hline urgency incontinence $(0=$ no, $1=$ yes $)$ & 1.46 & 0.85 & to & 2.49 \\
\hline feeling of incomplete emptying $(0=$ no, $1=$ yes $)$ & 2.18 & 1.29 & to & 3.68 \\
\hline bladder pain $(0=$ no, $1=$ yes $)$ & 0.90 & 0.29 & to & 2.73 \\
\hline urethral pain $(0=$ no, $1=$ yes $)$ & 2.32 & 0.55 & to & 9.91 \\
\hline
\end{tabular}

OR: odds rate; $95 \% \mathrm{Cl}$ : $95 \%$ confidence interval. 


\section{Discussion}

In this study, we investigated factors related to nocturia two or more times per night in the elderly who reside in low-lying mountainous areas. The results indicated that men who experience nocturia two or more times per night were older, had diabetes mellitus and/or lower back pain, and had lower urinary tract symptoms such as daytime frequency and urinary urgency. The female subjects were older, required a nursing care level of 1 or 2 , and had lower urinary tract symptoms such as urinary urgency and feeling of incomplete emptying. This study elucidated the fact that nocturia in elderly people who reside in low-lying mountainous areas is related to physical condition and lower urinary tract symptoms.

For both men and women, the factors related to change to a nocturia frequency of two or more times per night were aging and urinary urgency. There have been many previous reports on the relationship between nocturia and aging [11] [12] [13] with results similar to those of our study. In addition to lifestyle habits such as the consumption of caffeine and alcohol in the elderly, aging and illness also result in increased urinary volume during the night [14], leading to frequent urination. In addition, old age is characterized by lower sleep efficiency and longer amounts of time spent awake compared with young age [15]. Therefore, it is conceivable that going to the toilet because of the inability to sleep may lead to nocturia. It has been reported that nocturia and lower urinary tract symptoms are related in men and women [16]. The results of the present study indicated the same influence of lower urinary tract symptoms on nocturia. The present study found that among elderly men, nocturia of two or more times per night was related to diabetes mellitus, lower back pain, and daytime frequency. A previous study has also reported that in the elderly, nocturia of three or more times per night is related to diabetes mellitus [17], and it is conceivable that excessive urination owing to high blood sugar may lead to nocturia. In addition, a study of lower back pain in adults reported a relationship between physical pain and nocturia [18]. However, in the present study, the specific location of physical pain in the elderly male subjects was not elucidated. It is conceivable that in the elderly, the perception of pain may lead to awakenings during the night, which then results in an increased number of trips to the toilet to urinate, and it is also conceivable that lower back pain makes it difficult to exert abdominal muscle pressure or to perform movements required to eliminate waste. Among elderly men, daytime frequency was related to nocturia. In general, because men experience enlargement of the prostate as they age, both daytime and nocturnal urination increase. However, in the present study, because no relationship between nocturia and enlargement of the prostate was indicated, it is not possible to assert this with confidence. Nevertheless, because some of the elderly male subjects who were not diagnosed with enlargement of the prostate also had similar symptoms, it is conceivable that nocturia and frequent daytime urination are related. Among elderly women, however, nocturia of two times or more per night was related to requiring support 1 to requiring long-term care 2 and feel- 
ing of incomplete emptying. The elderly people recognizing from support 1 to support 2 have the tendencies to require the long-term care in the near future [19]. Another survey [20] indicated that the elderly people with requiring longterm care 1 or 2 decreased instrumental activities of daily living (IADL), activities of daily living (ADL) and the opportunities of social participation. Thus, they requiring from support 1 to long-term care 2 have lower almost daily activities, not only incontinence, than them without requiring. It also seems that the elderly people with requiring have toilet activities in advance before they fail in excretion due to low ADL and/or IADL, when they wake up in the night despite with/without micturition. The vesical capacity of elderly people decreases by atrophy of fibrosis and the tunica mucosa vesicae urinariae of the bladder smooth muscle with aging, and residual urine increases. Furthermore, urinary incontinence and urinary tract infection become easy to be caused because women have a shorter urethra than men. We suggest that nursing profession should care the elderlies with requiring from support to long-term care prophylactically not to aggravate subclinical inflammation of the bladder, especially among women with the feeling of residual urine, because elderies are hard to apper clinical symptoms such as fever.

The following are specific types of support. For men, to ensure that treatment of illnesses such as diabetes mellitus and lower back pain prevents worsening of nocturia, it is necessary for public health and hospital nurses to gather data related to the degree of nocturia and associated problems in daily life through routine medical examinations and outpatient visits and to provide information when necessary on how to handle these conditions. For women, it is necessary to provide support through educational activities related to nocturia and consultations in the early stages of the condition not only regarding the medical aspects of the disease but also regarding prevention when the level of long-term care need is low or prior to long-term care need. During classes for the prevention of nursing care and home visits, public health nurses should provide interventions in the form of providing information and offering consultations regarding nocturia and incontinence. In addition, for both men and women, medical examinations and home visits should be considered as opportunities for outpatient nurses to investigate whether patients have nocturia and lower urinary tract symptoms such as urinary urgency and to determine the severity and investigate how to provide support the patients after they are informed regarding the effect of these conditions on their daily lives.

According to a survey conducted by Uchida [21], nocturia at least once per night is related to community dwellers not going outdoors every day. In the present study, nocturia at least two times per night was seen in many elderly people who had the opportunity to go outdoors to visit the hospital. The elderly treated at medical facilities have illnesses or disabilities; therefore, it is possible that their illness may lead to an increase in nocturia. Hence, visits to local hospitals to undergo examinations may be considered as opportunities for hospital and public health nurses to conduct assessments of nocturia and its effect on daily life. In particular, there were more women who went outdoors for the 
purpose of shopping, work, hobbies, meeting friends, entertainment, and care of the grandchild in the Nocturia-1 group than those in the Nocturia- $\geq 2$ group. The purpose of these trips outdoors is to engage in social events that richen one's daily life and is considered to include elements of social participation, such as role fulfillment. We consequently believe that it is necessary to ascertain the overall lifestyle of elderly people to determine whether elderly women with an increase in nocturia to two or more times per night have fewer opportunities to participate in social activities.

\section{Limitations of This Study and Future Issues}

The following is a discussion on the limitations of this study and future issues. First, the response rate for this study was $75.9 \%$; however, the analysis set comprised up to only $56.1 \%$, which is not a high percentage. In addition, because the subjects were healthy elderly people who were members of senior citizen's clubs and that many of those who participated in this study were keen to participate, we cannot rule out the possibility of bias. Second, in this study, we compared nocturia once per night with that two or more times per night. Thus, we did not compare the related factors among multi-nocturia per night. In addition, some items were of low frequency, such as lower back pain in men and the level of long-term care need in women. In future, further studies based on the number of urinations per night must be conducted with a larger sample size. Third, the histories of current illness were self-reported, and as a result, they were not illnesses that had been medically diagnosed. However, with community-dwelling elderly people, this type of approach is possible.

\section{Conclusions}

The results of this study suggest that in community-dwelling elderly people, multiple episodes of nocturia per night are related to physical condition and lower urinary tract symptoms other than nocturia.

Support provided to community-dwelling elderly people should comprise contents tailored separately for men and women. For men to ensure that treatment of illness does not lead to worsening of nocturia while the condition is mild, data related to whether men experience nocturia and the degree of the condition should be gathered during medical examinations and outpatient visits, and when necessary, information should be provided to these men. For women, intervention in the form of providing information and consultations related to nocturia and incontinence should be provided at venues where women gather or through long-term care prevention classes. In addition, for supporting these men and women, it would be beneficial to investigate overall lifestyles to ascertain the degree of severity of lower urinary tract symptoms other than nocturia and their effect on people's daily lives.

\section{Acknowledgements}

We are grateful to Mr.Ryou Tachihara for collecting, sorting, and capturing data. 
This study was supported by JSPS KAKENHI Grant Number 26870381 (2014-2016).

\section{References}

[1] Aqarwal, A., Eryuzlu, L.N., Cartwright, R., Thorlund, K., Tammela, T.L., Guyatt, G.H., Auvinen, A. and Tikkinen, K.A. (2014) What Is the Most Bothersome Lower Urinary Tract Symptom? Individual- and Population-Level Perspectives for Both Men and Women. European Urology, 65, 1211-1217.

https://doi.org/10.1016/j.eururo.2014.01.019

[2] Honma, Y., Yamaguchi, O., Hayashi, K. and Members of the Neurogenic Bladder Society Committee (2006) Epidemiologic Survey of Lower Urinary Tract Symptoms in Japan. Urology, 68, 560-564. https://doi.org/10.1016/j.urology.2006.03.035

[3] Yoshimura, K., Kamoto, T., Oka, Y., Thukamoto, T., Oshiro, K., Suzukamo, Y., Kinukawa, N. and Ogawa, O. (2007) Differences between Bothersome and Non-Bothersome Night-Time Frequency. Neurourology and Urodynamics, 26, 1014-1019. https://doi.org/10.1002/nau.20451

[4] Kim, K., Uchiyama, M., Okawa, M., Liu, X. and Ogihara, R. (2000) An Epidemiological Study of Insomnia among the Japanese General Population. Sleep, 23, 41-47.

[5] Schatzl, G., Temml, C., Schmidbauer, J., Dolezal, B., Haidinger, G. and Madersbacher, S. (2000) Cross-Sectional Study of Nocturia in Both Sexes: Analysis of a Voluntary Health Screening Project. Urology, 56, 71-75. https://doi.org/10.1016/S0090-4295(00)00603-8

[6] Stewart, R.B., Moore, M.T., May, F.E., Marks, R.G. and Hale, W.E. (1992) Nocturia: A Risk Factor for Falls in the Elderly. Journal of the American Geriatrics Society, 40, 1217-1220. https://doi.org/10.1111/j.1532-5415.1992.tb03645.x

[7] Yoshimura, K. (2012) Correlates for Nocturia: A Review of Epidemiological Studies. Urology, 19, 317-329. https://doi.org/10.1111/j.1442-2042.2011.02956.x

[8] Ministry of Health. Summary of the Investigation of Care Service Institution and Long-Term Care Facilities for Fiscal Year 2015. (In Japanese) http://www.mhlw.go.jp/toukei/saikin/hw/kaigo/service15/dl/kekka-gaiyou_04.pdf

[9] Homma, Y., Yoshida, M., Yamanishi, T. and Gotoh, M. (2008) Core Lower Urinary Tract Symptom Score (CLSS) Questionnaire: A Reliable Tool in the Overall Assessment of Lower Urinary Tract Symptoms. International Journal of Urology, 15, 816-820. https://doi.org/10.1111/j.1442-2042.2008.02121.x

[10] Saito, T., Kondo, K., Murata, C., Joeng, S., Suzuki, K. and Kondo, N. (2015) Gender and Regional Differences in Going-Out, Social, and Leisure Activities among Older Adults Findings from the JAGES Project. Japanese Journal of Public Health, 62, 596-608.

[11] Johnson II, T.M., Sattin, R.W., Pamelee, P., Fultz, N.H. and Ouslander, J.G. (2005) Evaluating Potentially Modifiable Risk Factors for Prevalent and Incident Nocturia in Older Adults. Journal of the American Geriatrics Society, 53, 1011-1016. https://doi.org/10.1111/j.1532-5415.2005.53321.x

[12] Yu, H.J., Chen, T.H., Chie, W.C., Liu, C.Y., Tung, T.H. and Huang, S.W. (2005) Prevalence and Associated Factors of Nocturia among Adult Residents of the Matsu are of Taiwan. Journal of the Formosan Medical Association, 104, 444-447.

[13] Yoshimura, K., Oka, Y., Kamoto, T., Yoshimura, K. and Ogawa, O. (2010) Differences and Associations between Nocturnal Voiding/Nocturia and Sleep Disorders. BJU International, 106, 232-237. https://doi.org/10.1111/j.1464-410X.2009.09045.x

[14] Toba, K. (2003) Elderly Patients with Nocturia, Japanese Journal of Urological Sur- 
gery, 16, 29-31. (In Japanese)

[15] Mishima, K. (2011) The Sleep of Elderly People and the Disorder. The Journal of Therapy, 93, 205-211. (In Japanese)

[16] Tikkinen, K.A., Auvinen, A., Johnson II, T.M., Weiss, J.P., Keränen, T., Tiitinen, A., Polo, O., Partinen, M. and Tammela, T.L. (2009) A Systematic Evaluation of Factors Associated with Nocturia-The Population-Based FINNO Study. American Journal of Epidemiology, 170, 361-368. https://doi.org/10.1093/aje/kwp133

[17] Asplund, R. (2002) Nocturia in Relation to Sleep, Somatic Diseases and Medical Treatment in the Elderly. BJU International, 90, 533-536. https://doi.org/10.1046/j.1464-410X.2002.02975.x

[18] Asplund, R., Marnetoft, S.U., Selander, J. and Akerström, B. (2005) Nocturia in Relation to Somatic Health, Mental Health and Pain in Adult Men and Women. BJU International, 95, 816-819. https://doi.org/10.1111/j.1464-410X.2005.05407.x

[19] Izumi, K., Aso, Y. and Yamamoto, M. (2012) Factors Related to Care Levels after 5 Years in Elderly People with Lower Care Levels. Japanese Journal of Gerontology, 33, 538-554. (In Japanese)

[20] Miura, K., Kawagoe, M. and Koh, S. (2007) Characteristics of Functional Status among Requiring Community-Dwelling Frail Elderly. Journal of Human Life Science, 6, 95-104. (In Japanese)

[21] Uchida, Y. (2015) Lower Urinary Tract Symptoms affect Going Out in Community Residents. International Nursing Care Research, 14 1-7.

Submit or recommend next manuscript to SCIRP and we will provide best service for you:

Accepting pre-submission inquiries through Email, Facebook, LinkedIn, Twitter, etc. A wide selection of journals (inclusive of 9 subjects, more than 200 journals)

Providing 24-hour high-quality service

User-friendly online submission system

Fair and swift peer-review system

Efficient typesetting and proofreading procedure

Display of the result of downloads and visits, as well as the number of cited articles

Maximum dissemination of your research work

Submit your manuscript at: http://papersubmission.scirp.org/

Or contact health@scirp.org 